\title{
Ocorrência de Mancha Ocular em Milho Causada por Kabatiella zeae no Paraná e em Santa Catarina
}

\author{
Idalmir dos Santos, Alciani da Silva \& Gustavo Malagi \\ Universidade Tecnológica Federal do Paraná, Campus Pato Branco, Cx. Postal 571, CEP 85503-390, \\ Pato Branco, PR, Brasil, e-mail: idalmir@utfpr.edu.br
}

Autor para correspondência: Idalmir dos Santos

\begin{abstract}
Occurrence of Maize eyespot caused by Kabatiella zeae in Paraná and Santa Catarina state, Brazil

The eyespot in maize (Zea mays L.) was detected for the first time in Paraná and Santa Catarina state. The fungus

Kabatiella zeae was identified as etiologic agent of the disease.
\end{abstract}

\begin{abstract}
A mancha ocular em milho (Zea mays L.) foi descrita pela primeira vez no Japão em 1959. Em seguida, foi registrada nos Estados Unidos, Canadá, Argentina, Áustria, França, Alemanha, Iugoslávia e Nova Zelândia (Reifschneider \& Arny, Phytopathology 73:607. 1983). No Brasil, o único registro da doença foi em Dourados, MS, num trabalho conduzido para avaliar a incidência de doenças no milho, sob condições de infestação natural, em diferentes cultivares, no ano agrícola de 1982/83. A mancha ocular teve incidência baixa, ocorrendo nas cultivares AG 162 e Composto Pergamiño, das 14 avaliadas (Esteves, Fitopatol. Bras. 9:155. 1984). Folhas de milho dos híbridos Agroceres 9020, oriundas dos municípios de Campo Erê SC e Palmas PR foram recebidas no Laboratório de Microbiologia e Fitopatologia da UTFPR, Campus Pato Branco PR, em dezembro de 2004, apresentando os seguintes sintomas: lesões pequenas de 1 a 4 mm de diâmetro, com centro de cor parda, circulares ou ovais, cercadas por um anel encharcado, tornando-se, mais tarde, de cor marrom (Figura 1A). Quando colocadas contra a luz, as lesões apresentaram-se com centro mais escuro e borda mais clara, translúcida (Figura 1B). Quando visualizada ao microscópio estereoscópio, observouse facilmente o encharcamento ao redor das lesões (Figura 1C). Os sintomas observados coincidem com os da doença mancha ocular em milho causado por Kabatiella zeae Narita \& Y. Hirats., conforme a descrição de Arny et al. (Phytopathology 61:54. 1971). A maior intensidade da doença foi observada nas amostras de milho AG 9020 originárias de Campo Erê, onde as condições climáticas foram propícias à doença. Segundo Reis \& Casa (Manual de diagnose e controle de doenças do milho, 2.ed. 2004), a doença é favorecida por temperaturas amenas e clima úmido. No ano agrícola de 2005/2006 os mesmos sintomas foram observados nos híbridos Agroceres (AG) 9020, Agromem (AGN) 30A09 e AGN 30A06, em Pato Branco, PR. No mesmo município, no ano de 2007, a mancha ocular foi diagnosticada em 15 híbridos de milho (AG 8021, AGN 35A42, AGN 2012, Agroeste (AS) 1545, AS 3466, AS 1565, AS 32, AS 1560, Nidera (AX) 890, AX 892, AX 895, Dekalb (DKB) 566,
\end{abstract}

DKB 214, DKB 979 e Pioneer 32R21). O objetivo desta nota foi relatar a ocorrência da mancha ocular de cabatiela em milho nos estados de Santa Catarina e do Paraná. O fungo K. zeae foi isolado em BDA, de todos os híbridos de milho com mancha ocular, e após 12 horas e temperatura a $24^{\circ} \mathrm{C} \pm 2$, observaramse colônias de crescimento lento, rugosas, a princípio de cor creme, passando a rósea e finalmente negra leveduriforme (Figura 1D, E). Conídios do fungo foram observados no centro da colônia e em preparações microscópicas revelaram-se unicelulares, hialinos, curvos de 27,1 $\mu \mathrm{m}(19,6-34,3)$ x $3,8 \mu \mathrm{m}$ $(2,45-4,9)$ (Figura 1F). As dimensões dos conídios e demais características morfológicas citadas correspondem àquelas citadas por Arny et al. (Phytopathology 61:54. 1971) para o fungo Kabatiella zeae.

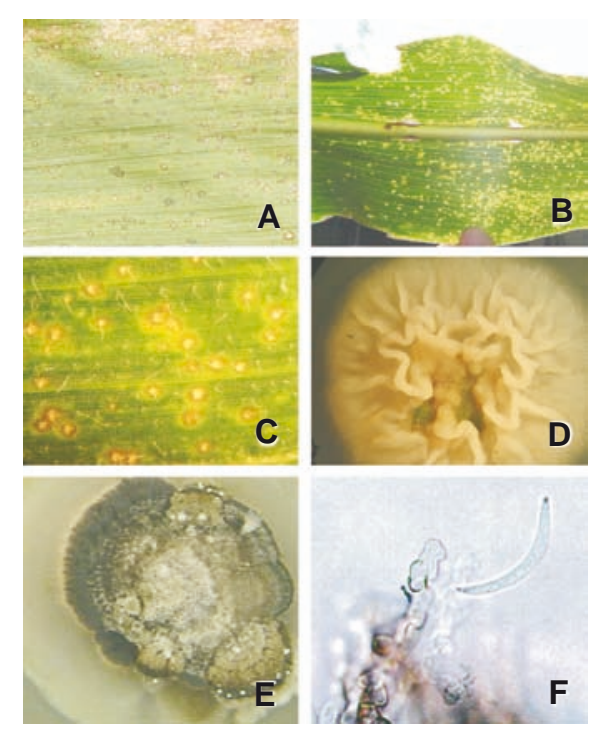

FIG. 1 -A. Sintomas de mancha ocular; B. sintomas vistos contra a luz; C. sintomas visualizados em microscópio estereoscópio; DE. colônia do fungo em BDA na fase inicial e em fase adiantada de desenvolvimento; F. conídio do fungo Kabatiella zeae. 